Raf. J. Sci.,Vol.28, No.2 Special Issue for the Third Scientific Conference of Chemistry, pp.152-163, 2019

\title{
Electrochemical Biosensor Hemoglobin Immobilization Determination of the Breast Cancer Drug (Adriamycin)
}

\author{
*Mohammed I. Mageed \\ Department of Chemistry/ College of Science/ University of Mosul \\ Eman A. Al-Jawadi \\ Department of Biophysics/College of Science/ University of Mosul \\ *E-mail: m_ihsan20@yahoo.com
}

(Received 18/9/2018; Accepted 25/ 10/2018)

\begin{abstract}
Electrochemical biosensor is an effective tool for pharmaceutical analysis due to its simplicity, specificity, sensitivity, fast, cost effective and repetitive measurements with miniaturized and portable devices. The paper illustrates the detail methodology for development of an electrochemical biosensor based on hemoglobin $(\mathrm{Hb})$ film modified for anticancer drug adriamycin (ADM). Square wave voltammetry (SWV) studies of the electrodes before and after immobilizing of HB shows the successful formation of a selectivity of the electrode. The proposed $\mathrm{Hb}$ based biosensor allows quantitation over the range 1 to $80 \times 10^{-8} \mathrm{M}$, The suggested biosensor method can be successfully applied to the detection and determination of anticancer drug adriamycin in different drug formulations and can be suggested as a suitable sensor for analysis of Adriamycin in biological samples.
\end{abstract}

Keywords: Electrochemical biosensor, Adriamycin, Hemoglobin, Breast cancer.

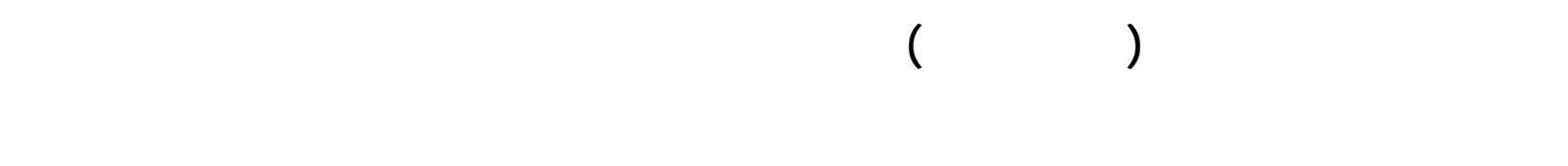

\section{المالخص}

أن المتعسلت الحيوية الكهروكيميائية وسيلة فاعلة في نقدير المستحضرات ال صصيدلانية بـ سببس هولة قطبيقته ا،

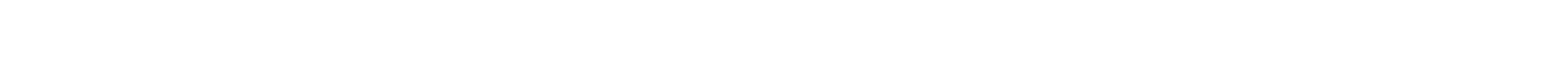
الثدي (الادريلمليسن) بلستخدلم تقنية فولتلمتري الموجة المربعة ومن خلال تحوير التطب الصلب فمع الهيموغلوبين حيث يمكن

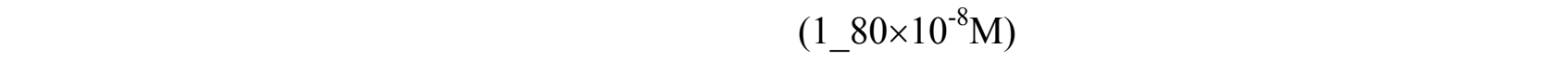
ويجعل المكانية ظبيقه على النماذج الحيوية ممكناً.

الهاملت الدالة: المتعسلت الحيوية، الادريلمليسين، الهيموغلوبينسرطلن الثدي.

\section{INTRODUCTION}

Cancer is a very serious health problem in all developed countries. Since the beginning of the $21^{\text {st }}$ century, cancer has becomes one of the most common primary causes of death, of which malignant breast tumors predominate for women (Risbridger et al., 2010; Cosimo and Baselga, 2010 ; Lin et al., 2010) and prostate cancer in men (Capitanio and Suardi, 2011; Lawrentschuk and Klotz, 2011; Oon et al., 2011). Treatment options are based on surgical removal of cancerous tissue, radiotherapy and chemotherapy. Chemotherapy approaches interfere with quite different cellular and molecular processes. Intercalators belong to the important group of drugs that are used in 
cancer therapy. Biosensor offers a very promising tool with its application in the field of pharmaceutical, biomedical and environmental compounds. For the last two decades, conducting polymers have emerged as one of the most interesting materials for the fabrication of biosensors and electrochemical sensors (Mulchandani and Wang, 1996).

\section{Adriamycin}

Adriamycin(ADM)(7S,9S)-7-[(2R,4S,5S,6S)-4-amino5-hydroxy-6-methyloxan-2-yl]oxy6,9,11-trihydroxy-9-(2hydroxyacetyl)-4-methoxy-8,10-dihydro-7H-tetracene-5,12dione. Fig. (1) is an anticancer (antineoplastic) chemotherapy drug classified as an anthracycline antiobiotic, commercialized in the form of chloride salt and sold as Adriamycin (Blum and Carter, 1974). Wide spectrum of chemotherapeutic applications and anti-neoplasic action widely used as an antitumor agent, and exhibits antitumor activity against solid tumors, such as breast and lung cancers (Ghirmai et al., 2005) is used in the treatment of various forms of sarcoma and cancer, including bladder cancer, breast cancer, leukemia, liver cancer, head and neck cancer, and lung cancer (Reza and Zahra, 2016).Its strong DNA binding properties lead the discoverers of the antibiotics to suggest that the drugs receptor site is DNA (Marco et al., 1964 ; Arcamone et al., 1969). Most of the available evidence indicates that it binds to double helix mainly at CG-GC steps, the amino sugar being determinant for intercalation to occur (Berg et al., 1981).

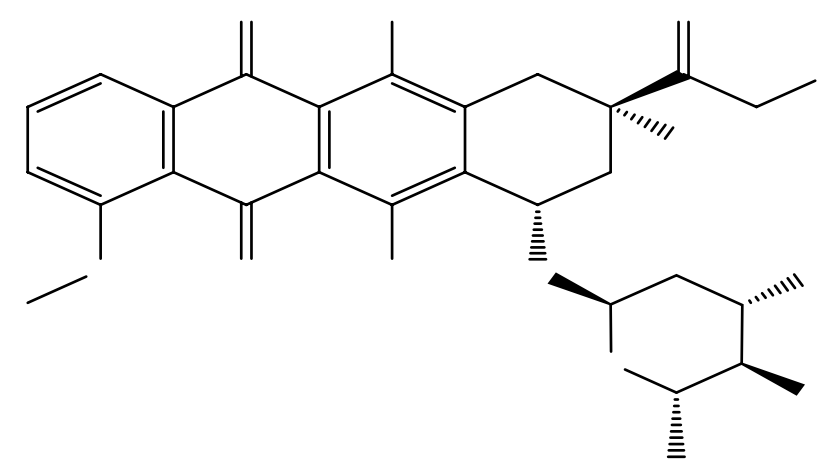

Fig. 1: Moleculare structure of adriamycin

\section{Biological Effect of Adriamycin}

Kiyomia et al. performed some experiments to identify the intracellular specificity of the differential cytotoxic effects of adriamycin on neoplastic and normal cells. These results suggest that adriamycin exerts cytostatic effects on neoplastic and normal undifferentiated cells through the inhibition of DNA synthesis by DNA intercalation, and cytotoxic effects on neoplastic cells through the accumulation of reactive oxygen species resulting from low scavenger enzyme activities. The cytotoxic effects on normal differentiated cells may be related to the high levels of production reactive oxygen species due to high mitochondrial NADH-cytochrome $\mathrm{C}$ reductase activity (Kiyomiya et al., 2001). Adriamycin is commonly used to treat some leukaemias, Hodgkin's and non- Hodgkin's lymphomas, as well as cancers of the bladder, breast, stomach, lung, ovaries, thyroid, soft tissue and bone sarcomas, multiple myeloma, among others.

\section{Reactive Oxygen Species Generation by Adriamycin and its Cardiotoxicity}

Generating reactive oxygen species causing lipoperoxidation that cause (amage cell membranes, apoptotic changes via interaction with iron ions and activation of NFKB belongs to the other important effect of adriamycin in vivo (Minotti et al., 2004; Keizer et al., 1990). The scheme of the effects of the generated radicals is shown in Fig.(2). Anthracyclines including adriamycin have long been said to induce cardiotoxicity by mechanisms other than those mediating their antitumor effectiveness, a concept which has raised hopes to design strategies for protecting the heart while not diminishing tumour response. Here we describe the most recent advances that may 
help to shed light into the mechanisms by which anthracyclines induce cardiotoxicity in experimental or clinical settings (Minotti et al., 2004; Singal and Iliskovic, 1998). To reduce their cardiotoxicity, nanoparticles based approaches for encapsulation of these drugs seems to be very convenient for this purpose (Patil et al., 2008).

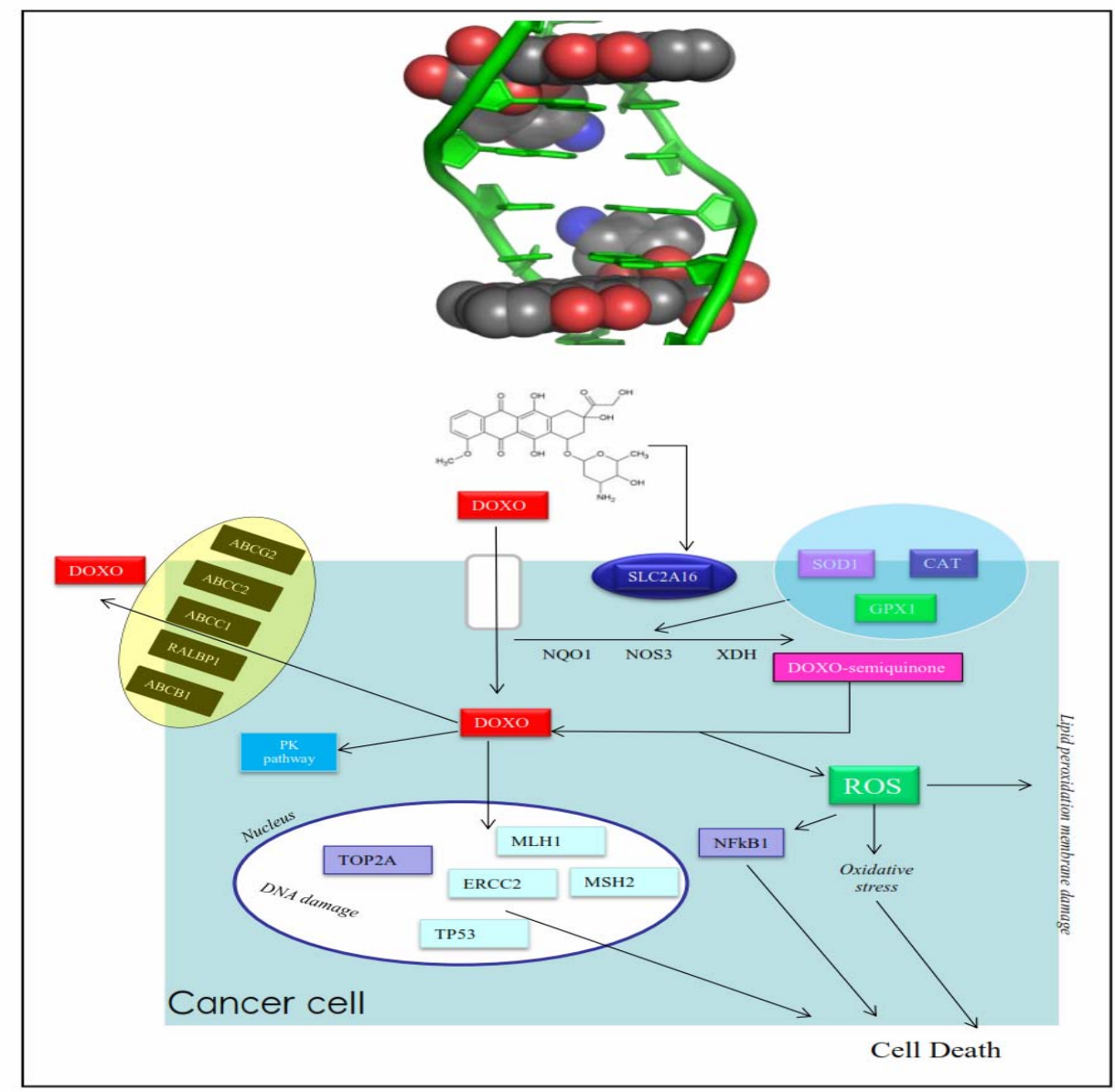

Fig. 2: Scheme of adriamycin interactions with different proteins in a cancer cell

\section{Adriamycin and Techniques Used}

The pharmacological effects of this drug have been ascribed to the interaction with double helix of DNA and the anthracycline moiety which causes inhibition of replication and transcription of DNA in cancer cells (Lown, 1993). However, clinical use of ADM is still limited for its cardiotoxicity that is usually caused by oxidative stress. Like all anthracyclines, ADM primarily works by intercalating DNA, but the mechanism of toxicity is also based on cell damage induced by reactive oxygen species, a mechanism in which free iron plays an important role. This opens a new field for the application of antioxidants (free radical scavengers and/or iron-chelating agents) in the potential protection of heart and other organs from ADM toxicity without impairing its antitumour efficacy (Injac and Strukelj, 2008). So, it is unequivocal that the development of sensitive and reliable analytical tools for the determination of ADM is a basic requirement for the study of this analyte in different types of samples with complex matrices. For this purpose, different analytical techniques have been used, and the most common among them is high performance liquid chromatography coupled with different detectors such as UV-Vis (Chin et al., 2002), tandem MS (Arnold et al., 2004; DiFrancesco et al., 2007), chemiluminescence (Ahmed et al., 2009), fluorimetric (DiFrancesco et al., 2007), and electroanalytical detectors (Ahmed et al., 2009). The capillary electrophoresis coupled with laser induced fluorescent detector (Anderson et al., 2003) is noted as another powerful hyphenated measurement technique for the separation and trace level determination of ADM and its intermediates from complex biological matrices. Besides, UV-Vis 
spectrophotometry (Siméon et al., 1999), fluorimetry (Liao et al., 2005), Raman spectroscopy (Liu and Danielsson, 2007), immuno assay analysis (Karukstis et al., 1998), and electroanalytical measurement techniques (Jemelkov et al., 2009 ; Hillard et al., 2008), have also been used for the determination of ADM in different samples. Electroanalytical methods represent an appropriate alternative to the above mentioned techniques, because of low cost of instrumentation, fast and sensitive performance of analysis, and simpler sample pretreatment procedures. Voltammetric methods, based on the use of different working electrodes, have proven to be convenient for the determination of this drug, thanks to the fact that its structure contains electroactive groups (Vacek et al., 2009). The determination of ADM is usually carried out using mercury-based electrodes (Forster, 1996 ) as well as different types of carbon based electrodes (Komorsky-Lovric, 2006 ). It is well known that ADM is strongly adsorbed in different electrode materials such as mercury (Yan et al., 1997), carbon paste, different types of graphite (Komorsky-Lovric, 2006), and glassy carbon (Jemelkov et al., 2009). This property has been utilized for electroanalytical determinations of ADM at trace levels (Baldwin et al., 1981). Besides, ADM was monitored by different electrodes in complex biological matrices, e.g. to assess its efflux from monolayers of cancer cells (Vacek et al., 2009), and later, from single isolated cells of the same cell lines (Oliveira-Brett et al., 2002), and in a case study on assessing transport at live cell preparations (Yi and Gratzl, 1998). Finally, electrochemical methods have been used in the exploratory investigation concerning the interaction of ADM and DNA (Nair and Gratzl, 2004).

Hemoglobin $(\mathrm{Hb})$ is a tetrameric protein that consists of four polypeptides and each polypeptide chain contains a heme group that serves as the active center (Kafi et al., 2007; Sun et al., 2004). It has been demonstrated that on conventional solid electrodes, the fast electron transfer between $\mathrm{Hb}$ and the electrode is not possible because of its deep entombing of the electroactive group in the structure of $\mathrm{Hb}$ (Gu et al., 2001).

Cancer is one of the most deadly diseases, and current detection options are ineffective. Recently, a large amount of research has been conducted for the development of biosensors which are able to detect cancer biomarkers. Many biosensors have been created for cancer detecting purposes. We examined literature reviews onlining current biosensing methods. These reviews provided an overview of the sensing techniques that are currently in existence as well as evaluation of their effectiveness. These paper help to showcase the feasibility and effectiveness that a biosensor has detecting cancer. In this paper I discuss the signal transduction systems, Electrochemical sensor, to use in cancer biosensors. Since cancer is such a deadly disease, an accurate biosensor is needed that can detect cancer earlier than current methods. In this paper, we will provide an overview of each method along with an evaluation to determine which cancer detecting system is the best.

\section{Instrumentation}

\section{EXPERIMENTAL SECTION}

Voltammetric measurements were carried out on 797 VA Computrace (Metrohm, Switzerland).

A conventional three electrode systems comprised were carried out using three electrodes cells, including Reference electrode (RE) as $\mathrm{Ag} / \mathrm{AgCl} 3 \mathrm{M} \mathrm{KCl}$ (metrohm, AG, 60728.020), $\mathrm{Pt}$ electrode was used as Auxiliray electrode (metrohm, AG, 6.0343,000). The $(3.0 \mathrm{~mm})$ bare Graphite electrode (Home made, Germany) as working electrode , graphite rod electrode was fabricated by sealing commercial graphite rods (diameter of $3.05 \mathrm{~mm}$; SGL Carbon, Bonn, Germany, www.sglgroup.com) in glass tubes (outer diameter $5 \mathrm{~mm}$ ) using epoxy glue (UHU plus endfest 300). All experiments were performed at room temperature $\left(25.0 \pm 0.5^{\circ} \mathrm{C}\right)$. The $\mathrm{pH}$ measurements were realized using a digital $\mathrm{pH}$ meter (HANNA, Portugal). For cleaning the working electrode ultrasonic cleaner was used (model; CD-4820, China). 


\section{Chemicals}

The ADM and its pharmaceutical dosage form were supplied from Koçak Farma Inc. (Istanbul, Turkey). Haemoglobin Bovine (molecular weight: 64,500) was supplied from HiMedia Laboratories Pvt. Ltd.( Mumbai, India). Phosphate, Tris-HCl and Britton Robinson buffers were used as supporting electrolytes. All solutions were protected from light and used within $24 \mathrm{~h}$ to avoid decomposition. chemicals were used of analytical reagent grade (Fluka, BDH) used as received without any further purification, and doubly distilled water was used throughout the experimental work.

\section{Cleaning and Polishing Electrode}

The $(3.0 \mathrm{~mm})$ Graphite electrodes (Home made, Germany), which were constrained in a glass rode, were polished with emery paper (P400/P800/P2000) and aluminaoxide in different (3.0 $\mu \mathrm{m}, 0.3 \mu \mathrm{m}, 0.1 \mu \mathrm{m}, 0.05 \mu \mathrm{m})$ repeatedly with afterwards thoroughly rinsed with double distilled water (we should be take care to rinsed with double distilled water after using every size of Alumina polish set ) then sonicated for $(15 \mathrm{~min})$ in double distilled water and allowed to air dry before further modification

\section{Preparation of the $\mathrm{Hb}$ Electrode}

Electropolymerisation of $\mathrm{Hb}$ at the surface of bare $\mathrm{GE}$ was carried out by using cyclic voltammetric method in aqueous solution containing $1.0 \times 10^{-3} \mathrm{M} \mathrm{Hb}$ in $0.2 \mathrm{M}$ PBS of $\mathrm{pH} 7.0$. The HB molecules are reduced to free radicals and rapidly combine with the GE surface.After 8 cycles, the peak currents remain constant; therefore, 8 cycles are chosen as a representative for the modification process. A uniform film is produced on GE surface, which indicates that the HB has been deposited on the GE surface by electropolymeriztion method.

\section{Voltammetric Behavior of ADM}

\section{RESULTS AND DISCUTION}

Voltammetric measurements were carried out in the presence of $0.2 \mathrm{M}$ PBS at $\mathrm{pH}(4.0-10.0)$ by square-wave voltammetry (SWV). In the case of model solutions of ADM, The analyze was added with a micropipette to the supporting electrolyte consisting $0.2 \mathrm{M}$ PBS (10.0 mL). the potential was swept in the range from $-1000 \mathrm{mV}$ to $-200 \mathrm{mV} v \mathrm{~s}$. $\mathrm{Ag} / \mathrm{AgCl}$, the peak potential at (-601) $m V$ under default conditions of the instrument (Fig 2) shows the square-wave voltammogram obtained for at $\mathrm{pH} 7$ of a bare graphite electrode

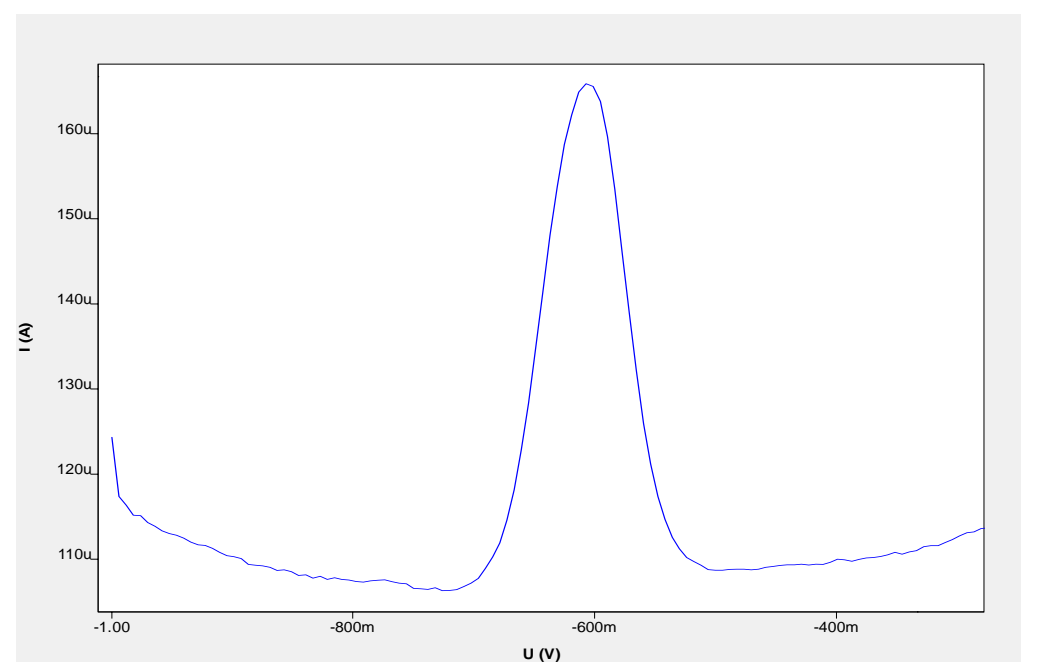

Fig. 2: square-wave voltammetry of ADM in $0.2 \mathrm{M}$ PBS at pH 7.0 


\section{Optimization of parameters for ADM}

To optimize the instrument parameter conditions for measurements by quare-wave voltammetry (SWV) ttechnique, the quare-wave voltammogram of (50.0) nM of ADM in phosphate buffer ( $\mathrm{pH}$ 7.0) was studied previously and was used as supporting electrolyte. The table below show the values of all parameters that give the best peak of ADM and these conditions were used for all measurements.

Table 1: Influence the variant conditions for (50.0) $\mathrm{nM}$ ADM in PBS(7.0) to give optimum peak resolution with higher current

\begin{tabular}{|c|c|}
\hline Optimum Condition & Values \\
\hline Start Potential (V) & -1.0 \\
\hline End Potential (V) & -0.2 \\
\hline Deposition potential (V) & -0.3 \\
\hline Deposition time (s) & 5 \\
\hline Equilibration time (s) & 5 \\
\hline Voltage step (V) & 0.0065 \\
\hline Amplitude (V) & 0.05 \\
\hline Frequency (Hz) & 60 \\
\hline
\end{tabular}

\section{Influence of $\mathrm{pH}$ and the structure of ADM}

In view of the fact that the ADM molecule contains a quinone functional group which is electroactive on Graphite electrode, a detailed study of the behavior of ADM at GE in the potential span from -1000 to $-200 \mathrm{mV}$ in the $0.2 \mathrm{M}$ phosphate buffer ( $\mathrm{pH} 4.0-10.0$ ) was performed by squarewave voltammetry. Based on the shape and intensity of the reduction signal of ADM, the $\mathrm{pH} 7.0$ was selected as an optimal value for the determination by SWV, while at $\mathrm{pH} 8.0$ to 10.0 a significant decrease of the peak current is observed. The obtained peak shifts to the more negative potentials with the increase in the $\mathrm{pH}$, and the plot of Ep versus $\mathrm{pH}$ is linear as shown in (Fig. 4), with the equation of best fit being: $\mathrm{Ep}=-0.328-0.038 \mathrm{pH}(\mathrm{r}=0.9903)$. All this indicates a complex

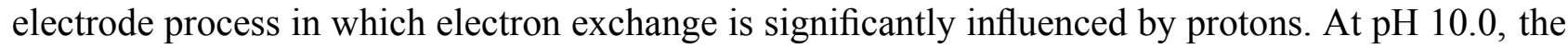
color of ADM solution becomes violet due to the conjugation in the quinone functional group.

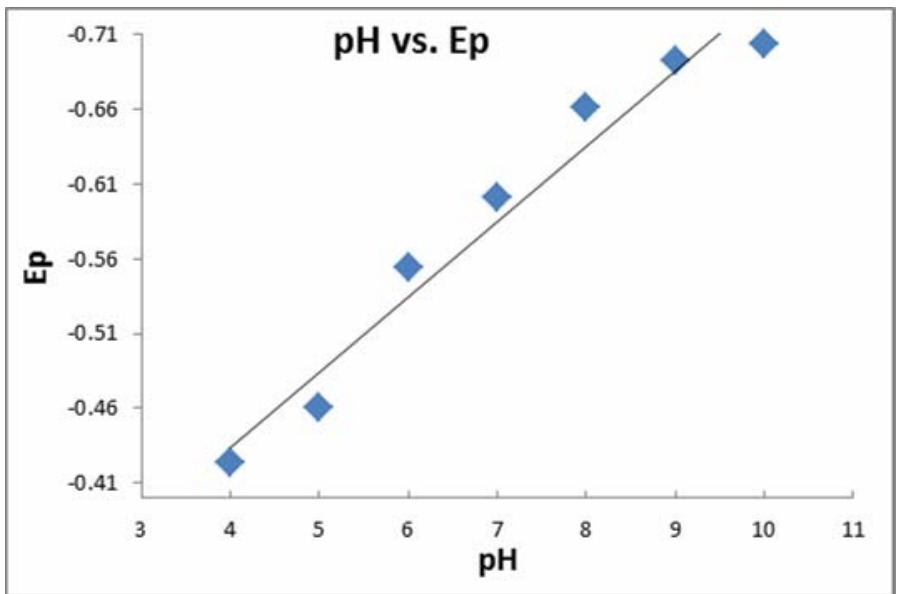

Fig. 4: The influence of the pH on the ADM signal obtained with GE $\left(50.10 \mathrm{ng} \mathrm{mL}^{-1}\right) \mathrm{by} \mathrm{SWV}$ and on the peak potential. 


\section{Reduction mechanism of ADM on graphite electrode}

The previous chronocoulometric measurements showed that the number of electrons involved in the reduction of another quinone molecule sodium 1,4-dihydroxy-9, 10-anthraquinone-2 sulphonate at the graphite electrode is two (Guin et al., 2010). Additionally, the extensively studied reaction of para-benzoquinone, having a similar electroactive center, showed that its reduction proceeds in two electron-transfer steps coupled with proton acceptance (He et al., 1990). Hence it seems plausible to think that the same process takes also place on the GE at $\mathrm{pH} 7.0$, and the overall reaction can be described as follows Fig. (5).<smiles>C=C(CC)[C@]1(C)Cc2c(c(C)c3c(=C)c4c([IH]C)cccc4c(=C)c3c2C)[C@@H](C[C@H]2C[C@H](C)[C@@H](C)[C@H](C)C2)C1</smiles><smiles>C=C(CC)[C@]1(C)Cc2c(c(C)c3c(C)c4c(CC)cccc4c(C)c3c2C)[C@@H](C[C@@H]2C[C@H](C)[C@@H](C)[C@H](C)C2)C1</smiles>

Fig. 5: Reduction mechanism of ADM on GE at pH 7.0.

\section{Effect of the concentration (calibration graph of ADM) using SWV}

The calibration curve of ADM was constructed using the optimum conditions in (Table 1). The SW. Voltammograms were recorded for serial additions of $\left(10^{-7}\right) \mathrm{M}$ ADM in P.B.S. ( $\mathrm{pH}$ 7.0) at $\left(25^{\circ} \mathrm{C}\right)$ using GE. The peak current plotted against the ADM concentration is shown in Fig. (6).

It is very clear that the intended Aation shous straight line, the stright line between the concentration range $\left(5 \times 10^{-7}-75 \times 10^{-7}\right) \mathrm{M}$ and Ip which gave a correlation coefficient $\left(\mathrm{R}^{2}=0.9756\right)$

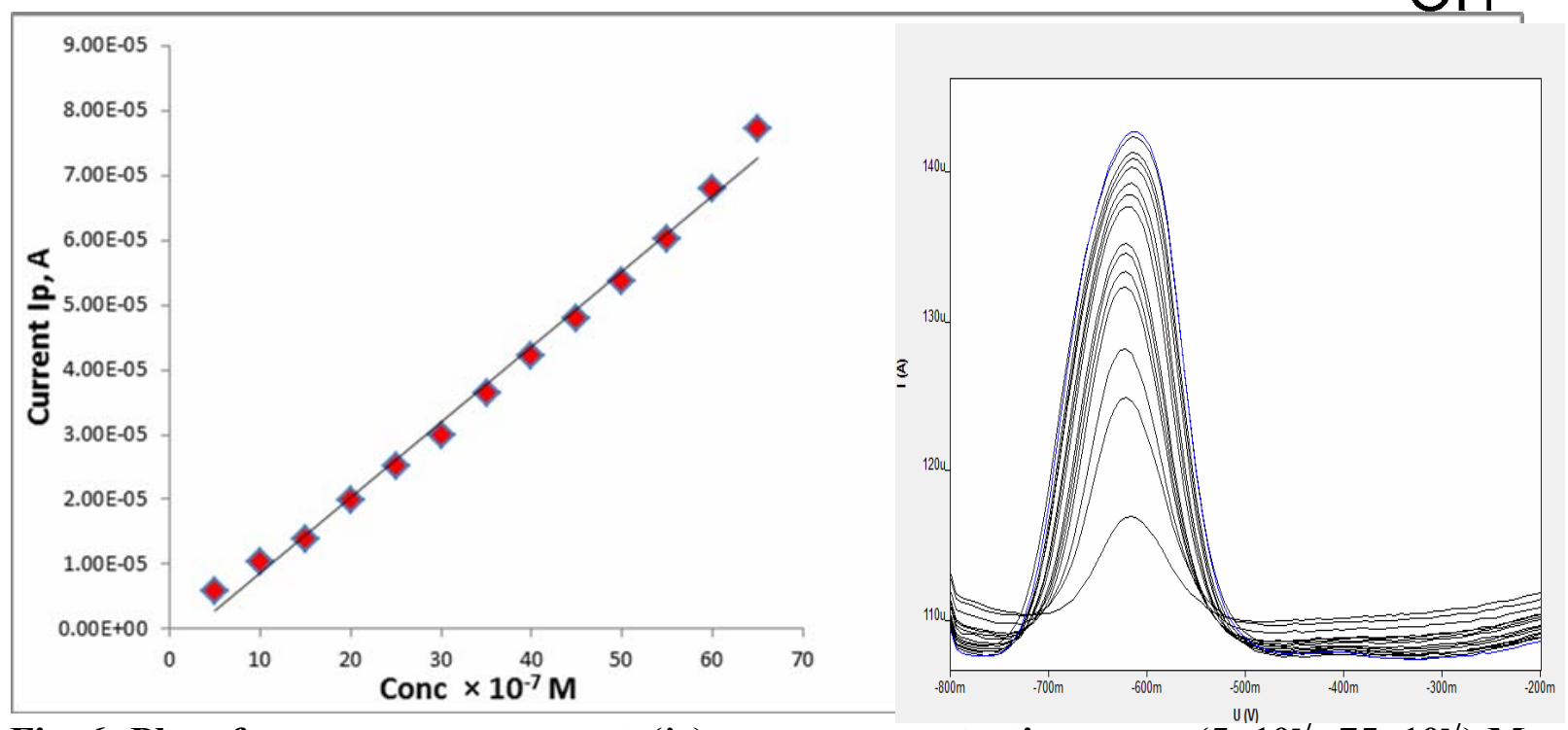

Fig. 6: Plot of current measurement (ip) versus concentration range $\left(5 \times 10^{-1}-75 \times 10^{-1}\right) \mathrm{M}$ of ADM

\section{Direct Electrochemistry of $\mathbf{H b}$}

In this paper, a film $\mathrm{Hb}$ was fixed on the surface of the GE with electrostatic growth mode. $\mathrm{Hb}$ (isoelectric points at 7.0) has considerable negative surface charges at $\mathrm{pH}$ 7.0. Hb showed good direct electron transfer behavior on the GE and the direct electrochemistry of $\mathrm{Hb}$ on the modified electrode was studied by cyclic voltammetry. 
Fig. (7), showed cyclic voltammograms of modified electrode in $\mathrm{pH} 7.0$ phosphate buffer solution. A pair of well defined, quasi-reversible cyclic voltammetric peaks (curve a)was found $\left(E p_{a}=-0.205 \mathrm{~V}\right)$ and $\left(E p_{c}=-0.251 \mathrm{~V}\right)$ at the scan rate $0.05 \mathrm{Vs}^{-1}$. The peaks were located at the potential characteristics of the heme $\mathrm{Fe}(\mathrm{III}) / \mathrm{Fe}(\mathrm{II})$ redox couples of proteins. The results indicated that all of the electroactive $\mathrm{Hb} \mathrm{Fe}$ (III) in the film was reduced to $\mathrm{Hb} \mathrm{Fe}(\mathrm{II})$ on the forward scan and then reoxidized to $\mathrm{Hb} \mathrm{Fe}(\mathrm{III})$ (Wei Sun et al., 2007).

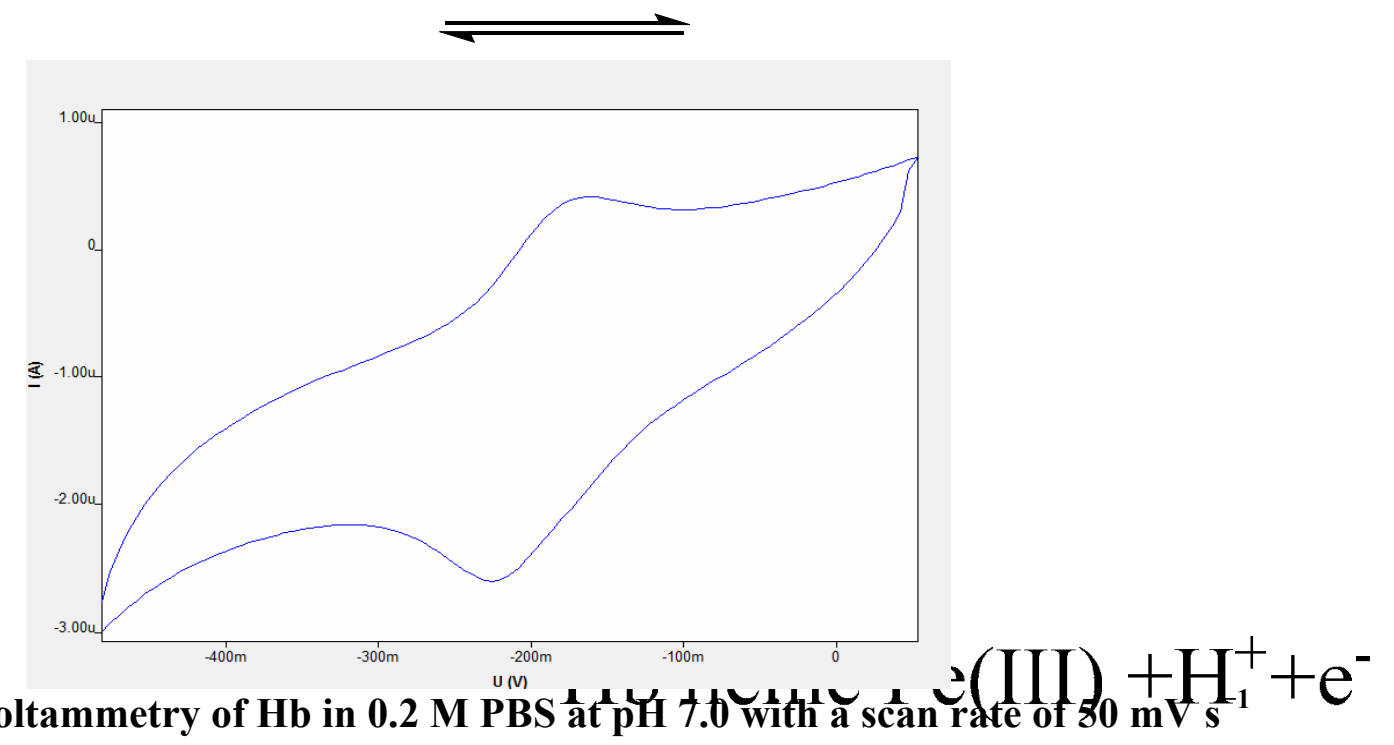

\section{Electropolymeriztion of HB onto GE}

Electropolymeriztion is a facile and efficient approach to immobilize an organic film onto solid state electrode surface because film properties, such as thickness, permeation and charge transportation, can be adjusted by controlling electrochemical parameters. Fig. (8) shows the successive $\mathrm{CV}$ curves during the electropolymeriztion of $\mathrm{HB}$ from a phosphate buffer solution $(\mathrm{pH} 7.0)$ containing $1.0 \times 10^{-3} \mathrm{M}$ HB. The HB molecules are reduced to free radicals and rapidly combine with the GE surface. After 8 cycles, the peak currents remain constant; therefore, 8 cycles are chosen as a representative for the modification process. A uniform film is produced on GE surface, which indicates that the HB has been deposited on the GE surface by electropolymeriztion method.

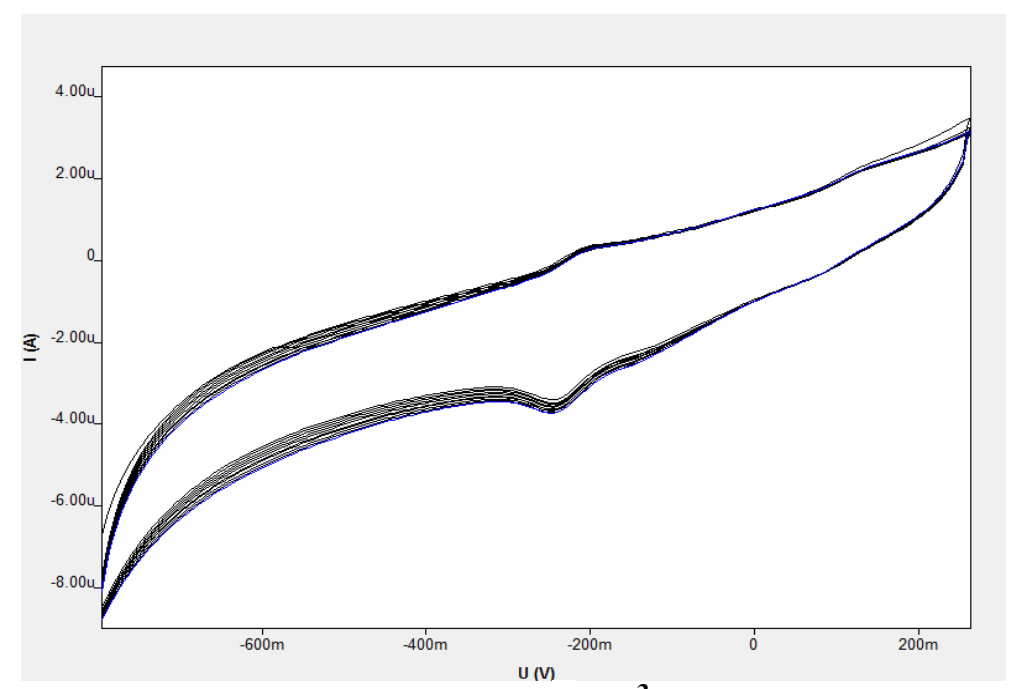

Fig. 8: Electropolymerization curves of $1.0 \times 10^{-3} \mathrm{M} \mathrm{Hb}$ in $10 \mathrm{ml} \mathrm{pH} 7.0 \mathrm{PBS}$ at GE Inset: the influence of the cycle and scan rate on the oxidation peak current 


\section{ADM determination of the $\mathrm{Hb}$ electrochemical biosensor}

The SWV technique was used to investigate the electrochemical behavior of the $\mathrm{G}$ bare and $\mathrm{G}$ modified electrodes in the attend ADM with the SWV sweeping from $-1000 \mathrm{mV}$ to $-200 \mathrm{mV}$ versus $\mathrm{Ag} / \mathrm{AgCl}$ reference electrode. Fig. (9) shows the electrochemical SWVs taken for $3.0 \times 10^{-8} \mathrm{M}$ to $3.0 \times 10^{-7} \mathrm{M}$ ADM on the surface PHb/GE. The current intensity as Fig. (9) shows the relationship between oxidation peak current and the ADM concentrations.

$\mathrm{Hb}$ in electron transfer boosting of the sensing layer can be attributed to its good anchoring to ADM, good electron mediatory, good electron pathway and favorable sensitivity and selectivity due to resulting $\mathrm{Hb} / \mathrm{GE}$ showed good electrocatalytic activity towards ADM reduction. Fig. (6) shows the SW. voltammograms obtained at the GE in the presence of different amounts of ADM. When ADM was added into $\mathrm{pH} 7.0$ buffer solution, the peak currents increased and enhanced due to the immobilized $\mathrm{Hb}$ film in the GE, which provided a fast direct electron transfer reaction between the heme of $\mathrm{Hb}$ and the electrode surface, heme can react with ADM to form a first intermediate of compound I, which has catalytic activity to ADM. The catalytic procedures can be explained as follows:
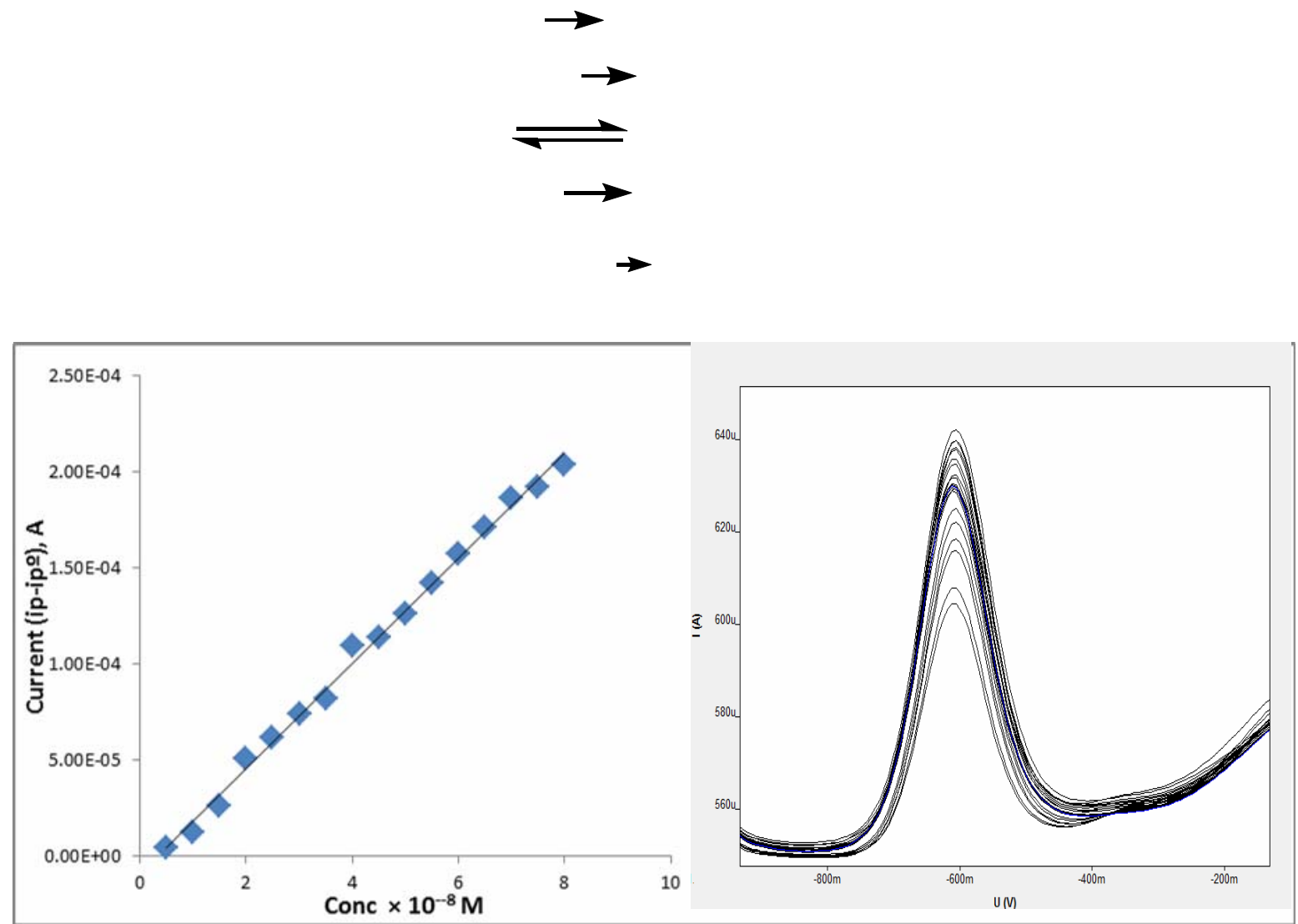

Fig. 9: Plot of current measurement (ip) versus concentration range $\left(3 \times 10^{-8}-3 \times 10^{-7}\right) \mathrm{M}$ of ADM on $\mathbf{p H b} / \mathrm{GE}$

\section{CONCLUSION}

\section{Compound I+ ADM}

In this work, an electrochemical sensor was fabricated based on modification by the direct

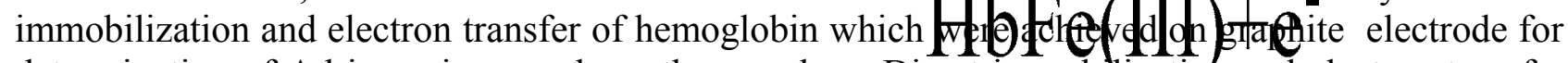
determination of Adriamycin as a chemotherapy drug. Direct immobilization and electron transfer of hemoglobin on GE can be established as a foundation for constructipg the new generation of

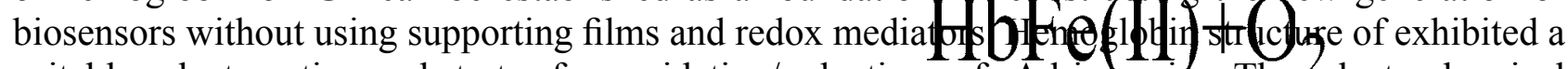
suitable electroactive substrate for oxidation/reduction of Adrianycin. The electrochemical parameters including: $\mathrm{pH}$, kind of buffer (Phosphate, Tris-Hff and Briton Rohinson huffers yere $\mathbf{Y}^{+}$

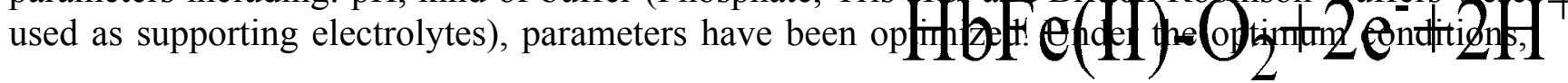


there was a good linear relationship between cathodic peak current and concentration of Adriamycin. The proposed method displayed excellent characteristics as simplicity, economy, good sensitivity, selectivity, reproducibility and rapid response, so it is suggested as a suitable sensor for the analysis of Adriamycin in biological samples.

\section{REFERENCES}

Ahmed, S.; Kishikawa, N.; Ohyama, K.; Wada, M.; Nakashima, K.; Kuroda, N. (2009). Selective determination of adriamycin and adriamycinol in rat plasma by HPLC with photosensitization reaction followed by chemiluminescence detection. Talanta, 78, 94.

Anderson, A.B.; Ciriacks, C.M.; Fuller, K.M.; Arriaga, E.A. (2003). Distribution of zeptomoleabundant Adriamycin metabolites in subcellular fractions by capillary electrophoresis with laser-induced fluorescence detection. Analytical Chem., 75, 8.

Arcamone, F.; Cassinelli, G.; Fantini, G.; Grein, A.; Orezzi, P.; Pol, C.; Spalla, C. (1969). Adriamycin, 14-hydroxy daunomycin, a new antitumor antibiotic from streptomyces peucetius var. caesius. Biotechnol. Bioeng., 11, 1101

Arnold, R.D.; Slack, J.E.; Straubinger, R.M. (2004). Quantification of Adriamycin and metabolites in rat plasma and small volume tissue samples by liquid chromatography/electrospray tandem mass spectroscopy. J. Chromatography B: Analytical Technol. in the Biomedical and Life Scie., 808, 141.

Baldwin, R.P.; Packett, D.; Woodcock, T. (1981). Electrochemical behavior of Adriamycin at carbon paste electrodes. Analytical Chem., 53, 540.

Berg, H.; Horn, G.; Luthardt, U.; Ihn, W. (1981). Interaction of anthracycline antibiotics with biopolymers: Part V. Polarographic behavior and complexes with DNA. Bioelectrochemistry and Bioenergetics, 8, 537.

Blum, R.H.; Carter, S.K. (1974). Adriamycin. A new anticancer drug with significant clinical activity. Annals Internal Med., 80, 249.

Capitanio, U.; Suardi, N. (2011). Prostate cancer in (2010). GSU: misclassification or biological progression. Nat. Rev. Urol., 8, 65.

Chin, D.L.; Lum, B.L.; Sikic, B.I. (2002). Rapid determination of PEGylated liposomal adriamycin and its major metabolite in human plasma by ultraviolet-visible high-performance liquid chromatography. J. Chromatography B: Analytical Technol. in the Biomedical and Life Sci., 779, 259.

Cosimo, S.D.; Baselga, J. (2010). Management of breast cancer with targeted agents: importance of heterogenicity. Nat. Rev. Clin. Oncol., 7, 139.

DiFrancesco, R.; Griggs, J.J.; Donnelly, J.; DiCenzo, R. (2007). Simultaneous analysis of cyclophosphamide, Adriamycin and adriamycinol by liquid chromatography coupled to tandem mass spectrometry. J. Chromatography B: Analytical Technologies in the Biomedical and Life Sci., 852, 545.

Forster, R.J. (1996). Kinetic separation of amperometric sensor responses. Analyst, 121, 733.

Ghirmai S.; Mume, E.; Tolmachev, V.; Sjobery, S. (2005). Synthesis and radioiodination of some daunorubicin and adriamycin derivatives. Carbohydr Res., 340, 15.

Gu, H.Y.; Yu, A.M.; Chen, H.Y. (2001). Direct electron transfer and characterization of hemoglobin immobilized on a Au colloid-cysteamine-modified gold electrode. $J$. Electroanal. Chem., 516, 119.

Hillard, E.A.; De Abreu, F.C.; Ferreira, D.C.M.; Jaouen, G.; Goulart, M.O.F.; Amatore, C. (2008). Electrochemical parameters and techniques in drug development, with an emphasis on quinones and related compounds. Chem. Communications, 2612.

Injac, R.; Strukelj, B. (2008). Recent advances in protection against adriamycin-induced toxicity. Technology in Cancer Research and Treatment, 7, 497. 
Jemelkov, Z.; Zima, J.; Barek, J. (2009). Voltammetric and amperometric determination of adriamycin using carbon paste electrodes. Collection Czechoslovak Chem.Communications, 74, 1503.

Kafi, A.K.M.; Lee, D.Y.; Park, S.H.; Kwon, Y.S. (2007). Amperometric biosensor based on direct electrochemistry of hemoglobin in poly-allylamine (PAA) film. Thin Solid Films, 515, 5179 .

Karukstis, K.K.; Thompson, E.H.Z.; Whiles, J.A.; Rosenfeld, R.J. (1998). Deciphering the fluorescence signature of daunomycin and adriamycin. Biophys. Chem., 73, 249.

Keizer, H. G.; Pinedo, H. M.; Schuurhuis, G. J.; Joenje, H. (1990). Doxorubicin (adriamycin): a critical review of free radical-dependent mechanisms of cytotoxicity. Pharmacol. Ther., 47, 219.

Kiyomiya, K.; Matsuo, S.; Kurebe, M. (2001). Cancer Chemotherapy. Pharmacol., 47, 51.

Komorsky-Lovric, S. (2006). Redox kinetics of adriamycin adsorbed on the surface of graphite andmercury electrodes. Bioelectrochem., 69, 82.

Lawrentschuk, N.; Klotz, L. (2011). Active surveillance for low-risk prostate cancer: an update. Nat. Rev. Urol., 8, 312.

Liao, L.B.; Zhou, H.Y.; Xiao, X.A. (2005). Spectroscopic and viscosity study of adriamycin Interaction with DNA. J. Molecular Structure, 749, 108.

Lin, S.X.; Chen, J.; Mazumdar, M.; Poirier, D.; Wang, C.; Azzi, A.; Zhou, M. (2010).Molecular therapy of breast cancer : progress and future direction . Nat. Rev. Endocrinol., 6, 485.

Lown, J.W. (1993). Anthracycline and anthraquinone anticancer agents: Current status and recent developments. Pharmacology and Therapeutics, 60, 185.

Marco, A.D.; Gaetani, M.; Orezzi, P.; Scarpinato, B. M.; Silvertrini, R.; Soldati, M.; Dasdia, T.; Valentini, L. (1964). The anthracyclines are members of the rhodomycin group of antibiotics produced bystreptomyces. Nature, 201,706

Minotti, G.; Menna, P.; Salvatorelli, E.; Cairo, G.; Gianni, L. (2004). Anthracyclines: molecular advances and pharmacologic developments in antitumor activity and cardiotoxicity. Pharmacol. Rev., 56, 185.

Mulchandani, A.K.; Wang, C.L. (1996). Bioenzyme sensors based modified electrode. Electroanal., 8, 414.

Nair, S.; Gratzl, M. (2004). Anomalies of deconvolution via discrete Fourier transform:A case study on assessing transport at live cell preparations. TrAC Trends in Analytical Chemistry, 23, 459.

Oliveira-Brett, A.M.; Piedade, J.A.P.; Chiorcea, A.M. (2002). Anodic voltammetry and AFM imaging of picomoles of adriamycin adsorbed onto carbon surfaces. J. Electroanalytical Chemistry, 538, 539-267.

Oon, S.F.; Pennington, S.R.; Fitzpatrick, J.M.; Watson, R.W.G. (2011). Biomarker research in prostate cancer-towards utility, not futility. Nat. Rev. Urol., 8, 131.

Patil, R.R.; Guhagarkar, S.A.; Devarajan, P.V. (2008). Engineered nanocarrier of doxorubicin: a current update. Crit. Rev. Ther. Drug Carr. Syst., 25,

Risbridger, G.P.; Davis, I.D.; Birrell, S.N.; Tilley, W. D. (2010). Breast and prostate cancer: more similar than different. Nat. Rev. Cancer, 10, 205.

Reza, H.; Zahra, T.; Nafiseh, S. (2016). Sensitive determination of doxorubicin in plasma and study on doxorubicin-DNA interactions using platinum electrode modified multi-walled carbon nanotubes. J. Pharmaceutical Analysis , 10, 1016

Siméon, N.; Chatelut, E.; Canal, P.; Nertz, M.; Couderc, F. (1999). Anthracycline analysis by capillary electrophoresis: Application to the analysis of daunorubicine in Kaposi sarcoma tumor. J. Chromatography A, 853, 449.

Singal, P.K.; Iliskovic, (1998). Doxorubicin-induced cardiomyopathy. N., N. Engl. J. Med., 339, 900. 
Sun, Y.; Liu, X.; Fan, C.; Zhang, W.; Li, G. (2004). Electrochemical investigation of the chloride effect on hemoglobin. Bioelectrochemistry. Bioelectrochem., 64, 23.

Vacek, J.; Havran, L.; Fojta, M. (2009). Ex situ voltammetry and chronopotentiometry of adriamycin at a pyrolytic graphite electrode: Redox and catalytic properties and analytical applications. Electroanalysis, 21, 2139.

Vacek, J.; Havran, L.; Fojta, M. (2009). The reduction of adriamycin at a mercury electrode and monitoring its interaction with DNA using constant current chronopotentiometry. Collection of Czechoslovak Chem. Communications, 74, 1727.

Yan, Q.; Priebe, W.; Chaires, J. B.; Czernuszewicz, R.S. (1997). Interaction of adriamycin and its derivatives with DNA: Elucidation by resonance Raman and surfaceenhanced resonance Raman spectroscopy. Biospectroscopy, 3, 307.

Yi, C.; Gratzl, M. (1998). Continuous in situ electrochemical monitoring of adriamycin efflux from sensitive and drug-resistant cancer cells. Biophysical J., 75, 2255.

Wei Sun; Ruifang Gao; Kui Jiao (2007). Electrochemistry and Electrocatalysis of Hemoglobin in Nafion/nano- $\mathrm{CaCO}_{3}$ film on a new ionic liquid $\mathrm{BPPF}_{6}$ Modified Carbon Paste Electrode. J. Phys. Chem. 111, 4560. 